\title{
Children with speech delay - A retrospective chart review
}

\author{
Vimalanathane. $\mathbf{P}^{1}$, Sivabalan. $\mathbf{E}^{2, *}$ \\ ${ }^{1}$ Junior Resident, ${ }^{2}$ Associate Professor, Dept. of Psychiatry, SRM Medical College and Research Centre, Kattankulathur, \\ Kanchipuram, Tamil Nadu, India
}

*Corresponding Author:

Email: drilasivabalan@yahoo.co.in

\begin{abstract}
Introduction: Speech delay is a common problem in children less than 6 years. The reported prevalence of language delay in children two to seven years of age ranges from 2.3 to $19 \%$. Various psychiatric disorders may manifest as speech delay in the early period. Usually, these children are initially seen by the primary care physician who gives reassurances and often fails to refer them to a psychiatrist. In these cases, the children miss out on the specialised assessment that they require and consequent help. Therefore, it is essential to evaluate each child with speech delay. Early identification and starting appropriate therapy as early as possible is very important for good clinical long term outcome. In this context, this study was carried out to investigate socio-demographic and other factors associated with speech delay.

Materials and Methods: A retrospective study design was used to collect data from case files of children aged less than 6 years who were referred to the psychiatric OPD for speech delay between May 2015 and May 2017. Their socio-demographic details, antenatal, perinatal and postnatal details, medical comorbidities, psychological assessment reports such as developmental and social quotient were collected and evaluated.

Results: In our study, speech delay was predominant in male child, middle and low socioeconomic status, semi-urban population \& nuclear family. Mild deficits in developmental and social functioning was found according to DST and VSMS.

Conclusion: This study's findings may prove relevant to therapists when planning comprehensive and effective treatment for such children.
\end{abstract}

Keywords: Speech delay, Specific developmental disorders of speech and language, Pervasive developmental disorders, Mental retardation.

\section{Introduction}

Speech is the verbal production of thought, whereas language is the conceptual processing of communication. Language includes both the capacity to understand, "receptive language", and the ability to convey information, emotions and ideas, or "expressive language". Developmental language delay has been a concern of those interested in the developmental of children. According to Rutter and Martin, ${ }^{1}$ this issue can have a great impact on the child's future for a number of reasons. First, delayed language development means that the child may have difficulty in communicating with others and thus may be disadvantaged. Second, in young children it may be the first manifestation of a more pervasive disorder such as mental retardation, learning disability or behavioural problem. Third, it may lead directly to problems with learning and behaviour. Finally, it may predict, in a subtle manner, future learning disabilities such as difficulties in reading and writing. Several studies have shown that children with speech and language problems at two and a half to five years of age have increased difficulty reading in the elementary school years. ${ }^{2-4}$ Beyond five and a half years, persistent language impairment can result in attention and social difficulties. ${ }^{5}$ When this lasts beyond 7 and a half to 13 years, it can result in deficits in writing skills, and in spelling and punctuation when compared to those children without speech and language impairments. ${ }^{6}$ The reported prevalence of language delay in children two to seven years of age ranges from 2.3 to 19 percent. $^{7-11}$ Leske's ${ }^{12}$ data suggests $2.5-3 \%$ prevalence of speech-language disorders in 3-5-year-old children. Hull et al. ${ }^{13}$ \& Beitchman et al., ${ }^{14}$ found $9-11 \%$ prevalence rates for first-grade children, while L. D. Shriberg et $\mathrm{al}^{15}$ estimated the prevalence of $3.8 \%$ speech delay in 6-year old children. A critical review of the literature concerning the prevalence of psychiatric disorders in children with speech and language retardation revealed that such children are at risk for the occurrence of disorders such as attentional deficit disorder, oppositional disorder and various anxiety disorders. ${ }^{16}$ Usually, these children are initially seen by the primary care physician who gives reassurances and often fails to refer them to a psychiatrist. In these cases, the children miss out on the specialised assessment that they require and consequent help they need. Therefore, it is essential to evaluate each child with speech delay. Early identification and starting appropriate therapy as early as possible is very important for good clinical longterm outcome.

\section{Materials and Methods}

It is a retrospective study. The study was conducted at SRM hospital, Chennai. Data were collected from the case files of children aged less than 6 years who were referred to the psychiatric OPD for speech delay with normal hearing between May 2015 and May 2017.

\section{Inclusion Criteria}

1. Children less than 6 years of age 
2. Intact hearing

3. Completion of intellectual assessment by means of DST/VSMS

\section{Exclusion Criteria}

1. Children above 6 years of age

2. Hearing Loss

3. Lack of intellectual assessment by means of DST/VSMS

Their socio-demographic details such as sex, age, religion, socioeconomic status, parent's consanguinity, type of family and place of residence were collected.

Their antenatal details such as mother's medical comorbidities in the antenatal period, maturity such as preterm or full term or post term baby, perinatal details such as type of delivery, birth cry was either immediate or delayed or absent, incubator history and postnatal events such as seizure history were collected.

Their psychological assessment reports such as Developmental screening test (DST) and Vineland Social Maturity Scale (VSMS) scores were collected.

DST is used for measuring mental development of a child. A semi-structured interview is conducted with the child and parents. There are 88 behavioural items presented at appropriate age levels. Scores obtained on these items with IQ calculator are used to assess the level of development in the child and these scores are expressed in terms of their "developmental age" or "developmental quotient".

Vineland Social Maturity Scale (VSMS) is designed to measure social competence, defined as a "functional composite of human traits that sub-serve social usefulness and are reflected in self-sufficiency and in service to others", from birth to 30 years of age. It measures eight categories of behaviour: "self-help general, self-help eating, self-help dressing, locomotion, occupation, communication, self-direction, and socialization". The parent or someone familiar with the child is interviewed, and behaviours that are usually shown by the children are noted, and scores are given accordingly. This score is then expressed as "social age" or "social quotient".

\section{Results}

In accordance with the criteria, a total of 210 files from May 2015 to May 2017 were reviewed. 104 files were excluded as they either did not include an intellectual assessment or were of children with physical disabilities such as hearing impairment that contributed to their speech delay. 106 files were ultimately selected for the study.

Table 1 lists the socio-demographic, antenatal, perinatal and postnatal history variables and percentage. Considering the socio-demographic characteristics of the children, we found that a majority $(53.8 \%)$ were from the 3-5 year age group, male (73.6\%) and Hindu (84\%). The families that they belonged to tended to be of middle $(49.1 \%)$ or low $(48.1 \%)$ socioeconomic class, nuclear type $(84.9 \%)$, residing in a semi-urban area $(54.7 \%)$. The parent's marriage was usually nonconsanguineous $(82.1 \%)$. Chart 1 describes the sociodemographic details.

A vast majority of the mothers of the children reviewed $(81 \%)$ did not suffer from complications during the antenatal period, and carried their children to full term $(87.7 \%)$ with only $11.3 \%$ of children being born pre-term. Children cried immediately after birth in $82.1 \%$ of the files studied and incubator was not required for $74.5 \%$ of children. Most children did not suffer from any adverse postnatal events, with seizures accounting for $15.1 \%$ of cases. Chart 2 describes the antenatal, perinatal \& postnatal details.

Table $2 \& 3$ lists the DST and VSMS variables and percentage. Upon assessment of developmental and social adaptive function using the DST and VSMS, we found that the generally scored as having mild deficit $(36.8 \%$ \& $33 \%)$ and borderline deficit $(17.9 \%$ \& $22.6 \%$ ) respectively. Only $9.4 \%$ of children had normal/average developmental quotient and $5.7 \%$ had normal/average social quotient. Chart 3 describes the DST and VSMS details.

Table 1: Socio-demographic, antenatal, perinatal and postnatal history

\begin{tabular}{|c|c|c|c|}
\hline \multicolumn{2}{|l|}{ Variables } & \multirow{3}{*}{$\begin{array}{c}\text { Frequency } \\
41\end{array}$} & \multirow{3}{*}{\begin{tabular}{|c|} 
Percent \\
38.7 \\
\end{tabular}} \\
\hline & & & \\
\hline \multirow[t]{3}{*}{ Age } & $1-3$ & & \\
\hline & $3-5$ & 57 & 53.8 \\
\hline & Above 5 & 8 & 7.5 \\
\hline \multirow[t]{2}{*}{ Sex } & Male & 78 & 73.6 \\
\hline & Female & 28 & 26.4 \\
\hline \multirow[t]{3}{*}{ Religion } & Hindu & 89 & 84.0 \\
\hline & Christian & 10 & 9.4 \\
\hline & Muslim & 7 & 6.6 \\
\hline \multirow{3}{*}{$\begin{array}{l}\text { Socio } \\
\text { Economic } \\
\text { Status }\end{array}$} & High & 3 & 2.8 \\
\hline & Middle & 52 & 49.1 \\
\hline & Low & 51 & 48.1 \\
\hline \multirow[t]{2}{*}{ Consanguinity } & \begin{tabular}{|c|} 
Non \\
Consanguineous \\
\end{tabular} & 87 & 82.1 \\
\hline & \begin{tabular}{|l|} 
Consanguineous \\
\end{tabular} & 19 & 17.9 \\
\hline \multirow{2}{*}{$\begin{array}{l}\text { Type of } \\
\text { Family }\end{array}$} & Nuclear & 90 & 84.9 \\
\hline & Joint & 16 & 15.1 \\
\hline \multirow{3}{*}{$\begin{array}{l}\text { Area of } \\
\text { Resident }\end{array}$} & Urban & 18 & 17.0 \\
\hline & Semi Urban & 58 & 54.7 \\
\hline & Rural & 30 & 28.3 \\
\hline \multirow[t]{2}{*}{ Antenatal } & $\begin{array}{c}\text { Medical } \\
\text { comorbidities }\end{array}$ & 17 & 16.0 \\
\hline & Nil & 89 & 84.0 \\
\hline \multirow[t]{3}{*}{ Term } & Pre Term & 12 & 11.3 \\
\hline & Full Term & 93 & 87.7 \\
\hline & Post Term & 1 & 0.9 \\
\hline \multirow[t]{4}{*}{ Delivery } & Normal & 51 & 48.1 \\
\hline & $\begin{array}{l}\text { Caesarian } \\
\text { Section }\end{array}$ & 51 & 48.1 \\
\hline & Forceps & 3 & 2.8 \\
\hline & Vacuum & 1 & 0.9 \\
\hline \multirow[t]{2}{*}{ Birth cry } & Immediate & 87 & 82.1 \\
\hline & Delayed & 9 & 8.5 \\
\hline
\end{tabular}




\begin{tabular}{|l|c|c|c|}
\hline & Absent & 10 & 9.4 \\
\hline \multirow{2}{*}{ Incubator } & Yes & 27 & 25.5 \\
\cline { 2 - 4 } & No & 79 & 74.5 \\
\hline \multirow{2}{*}{$\begin{array}{l}\text { Postnatal } \\
\text { events }\end{array}$} & Nil & 87 & 82.1 \\
\cline { 2 - 4 } & Seizure & 16 & 15.1 \\
\cline { 2 - 4 } & CHD & 3 & 2.8 \\
\hline
\end{tabular}

Chart 1:

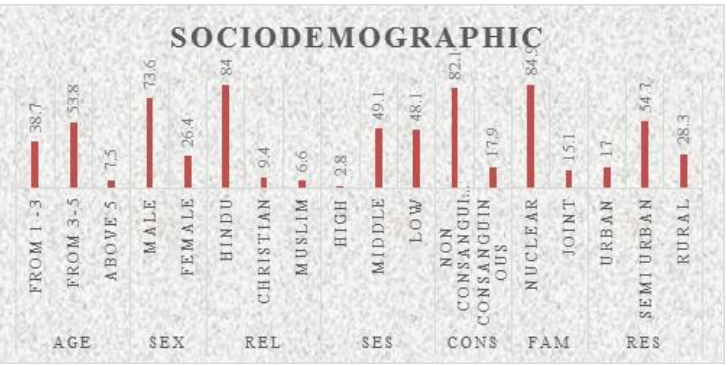

Chart 2:

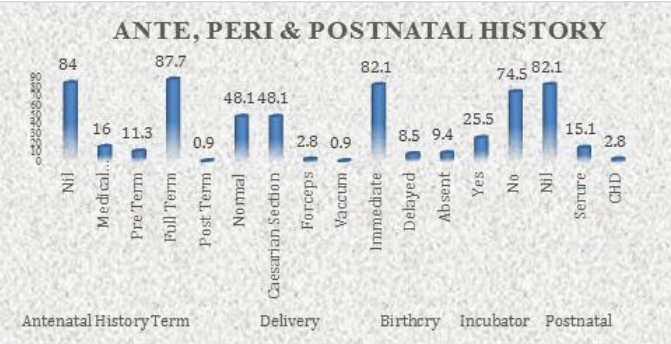

Table 2: DST

\begin{tabular}{|l|c|c|}
\hline & Frequency & Percent \\
\hline Genius & 1 & .9 \\
\hline Superior Intelligences & 1 & .9 \\
\hline $\begin{array}{l}\text { Normal or Average } \\
\text { Intelligence }\end{array}$ & 10 & 9.4 \\
\hline $\begin{array}{l}\text { Below Average or } \\
\text { Dullness }\end{array}$ & 11 & 10.4 \\
\hline Borderline Deficit & 19 & 17.9 \\
\hline Mild deficit & 39 & 36.8 \\
\hline Moderate deficit & 13 & 12.3 \\
\hline Severe deficit & 9 & 8.5 \\
\hline Profound deficit & 3 & 2.8 \\
\hline Total & 106 & 100.0 \\
\hline
\end{tabular}

Table 3: VSMS

\begin{tabular}{|l|c|c|}
\hline & Frequency & Percent \\
\hline Genius & 1 & .9 \\
\hline Superior Intelligences & 4 & 3.8 \\
\hline $\begin{array}{l}\text { Normal or Average } \\
\text { Intelligence }\end{array}$ & 6 & 5.7 \\
\hline $\begin{array}{l}\text { Below Average or } \\
\text { Dullness }\end{array}$ & 18 & 17.0 \\
\hline Borderline Deficit & 24 & 22.6 \\
\hline Mild deficit & 35 & 33.0 \\
\hline Moderate deficit & 9 & 8.5 \\
\hline Severe deficit & 6 & 5.7 \\
\hline Profound deficit & 3 & 2.8 \\
\hline Total & 106 & 100.0 \\
\hline
\end{tabular}

\section{Chart 3:}

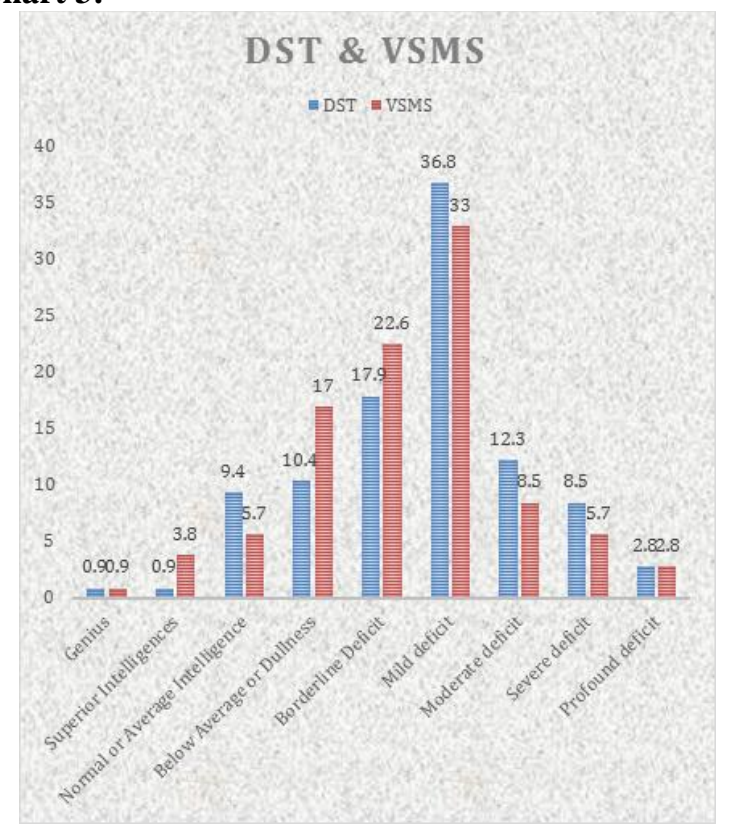

\section{Discussion}

Silva ${ }^{9}$ reported about the longitudinal study by the Dunedin (New Zealand) multidisciplinary health and development research unit, which found that a delay in language development is associated with both low intelligence and reading difficulties. Our study found a correlation between deficits in developmental and social function and speech delay.

Some types of deficits in language development are hypothesised to be because of abnormalities in brain structure and function. It can be said that in these cases it is likely the psychiatric disorder is due to the damage to the brain as much as it is due to the language disorder. As a vast majority of the individuals with an Intelligence Quotient below 50 are known to have abnormalities in brain structure, it is possible that both the psychiatric disorder and language delay in such children is due to the gross brain disease. ${ }^{17}$

A number of studies have revealed a specific association between large family size, low verbal intelligence, poor reading skills, and conduct disorders ${ }^{18-19}$. Larger family size has not been specifically associated in this manner with other psychiatric disorders or non-verbal intellectual deficits. This association may be hypothesised to be due to differing patterns of family life in nuclear and joint families. In the latter, there may be less intensive interaction between multiple family members and more exposure to other children with small vocabularies and poor grammar. ${ }^{20-21}$ However, our study revealed that nuclear families had more children with speech delay which may suggest that a lack of sustained interaction with other people and other children could contribute to a delay in speech development.

There is much evidence linking socioeconomic class and language or speech disorders. A 1956 study 
by Barry and Eisenson ${ }^{22}$ found that speech disorders were more prevalent among children belonging to families of a lower socio-economic class. These findings may be somewhat unreliable as the language tests used could have cultural biases. However, size of vocabulary and complexity of sentence structures tests, which are not quite as culturally sensitive, revealed poorer developmental skills among children belonging to lower socio-economic class. Our results concur with these findings.

Identification of these children with language developmental delay at an early stage can lead to effective early intervention which may be useful ${ }^{23}$. However more research is required in this area. It will be helpful to see if early intervention can help ease the long-term effects of speech/language delay, well into their school going years and adulthood.

\section{Conclusion}

Speech delay in children is a common problem. Usually, these children are initially seen by the primary care physician who gives reassurances and often fails to refer them to a psychiatrist. In these cases, the children miss out on the specialised assessment that they require. In this study, we found that almost $80 \%$ of children with speech delay have deficits in their developmental and social functioning. This deficit may be a cause of speech delay or an underlying pathology in the brain may cause intellectual disability and speech delay. Many studies found that speech delay also presents with attention difficulties, hyperactivity and learning difficulties. So these children need holistic psychiatric assessment at an early stage and plan for further management accordingly.

Further Directions: A prospective comparative study may reveal a more reliable finding on the relationship between intellectual ability and speech delay. Follow up these patients will give a better understanding of the developmental processed involved in speech production and speech delay.

\section{References}

1. Rutter, M., Martin, J. A. M. (1972) the Child with Delayed Speech. Clinics in Developmental Medicine, No. 43. London: S.I.M.P. with Heinemann.

2. Catts HW, Fey ME, Tomblin JB, Zhang X. A longitudinal investigation of reading outcomes in children with language impairments. J Speech Lang Hear Res. 2002;45 (6):1142-1157.

3. Scarborough HS, Dobrich W. Development of children with early language delay. J Speech Hear Res. 1990;33(1):70-83.

4. Silva PA, Williams S, McGee R. A longitudinal study of children with developmental language delay at age three: later intelligence, reading and behaviour problems. Dev Med Child Neurol. 1987;29(5):630-640.

5. Snowling MJ, Bishop DV, Stothard SE, Chipchase B, Kaplan C. Psychosocial outcomes at 15 years of children with a preschool history of speech language impairment. J Child Psychol Psychiatry. 2006;47(8):759-765.
6. Bishop DV, Clarkson B. Written language as a window into residual language deficits: a study of children with persistent and residual speech and language impairments. Cortex. 2003;39(2):215-237.

7. Burden V, Stott CM, Forge J, Goodyer I. The Cambridge Language and Speech Project (CLASP). I. Detection of language difficulties at 36 to 39 months. Dev Med Child Neurol. 1996;38(7):613-631.

8. Stevenson J, Richman N. The prevalence of language delay in a population of three-year-old children and its association with general retardation. Dev Med Child Neurol. 1976;18(4):431-441.

9. Silva PA, McGee R, Williams SM. Developmental language delay from three to seven years and its significance for low intelligence and reading difficulties at age seven. Dev Med Child Neurol. 1983;25(6):783793.

10. Rescorla L, Hadicke-Wiley M, Escarce E. Epidemiological investigation of expressive language delay at age two. First Language. 1993;13:5-22.

11. Wong V, Lee PW, Lieh-Mak F, et al. Language screening in preschool Chinese children. Eur J Disord Commun. 1992;27(3):247-264.

12. Leske, M. (1981). Prevalence estimates of communicative disorders in the United States: Speech disorders. Asha, 23, 217-228.

13. Hull, F. M., Mielke, P. W., Jr., Timmons, R. J., \& Willeford, J. A. (1971). The national speech and hearing survey: Preliminary results. Asha, 13, 501-509.

14. Beitchman, J. H., Nair, R., Clegg, M., \& Patel, P. G. (1986). Prevalence of speech and language disorders in 5year-old kindergarten children in the Ottawa-Carleton region. Journal of Speech and Hearing Disorders, 51, 98110.

15. Shriberg L. D., Tomblin J. B., \& McSweeny J. L. (1999). Prevalence of speech delay in 6-year-old children and comorbidity with language impairment. Journal of Speech, Language, and Hearing Research, 42, 14611481.

16. Baker, L. \& Cantwell, D. P. (1977), Psychiatric disorder in children with speech and language retardation. Arch. Gen. Psychiat., 34:583-591.

17. Shaffer D: Psychiatric aspects of brain injury in childhood: A review. Dev Med Child Neurol 15:211-220, 1973.

18. Clausen JA: Family structure, socialization and personality, in Hoffman L, Hoffman M (eds): Review of Child Development. New York, Russell Sage Foundation, 1966, vol 2.

19. Douglas JWB, Ross JM, Simpson HR: All Our Future. London, Peter Davies Ltd, 1968.

20. DeVito JA: Speech and language acquisition: Developmental psycholinguistics, in Psychology of Speech and Language: An Introduction to Psycholinguists. New York, Random House Inc, 1970, pp 111-150.

21. Scott R, Seifert K: Family size and learning readiness profiles of socioeconomically disadvantaged preschool whites. J Psychol 89:3-7, 1975.

22. Berry MF, Eisenson J: Speech Disorders: Principles and Practices of Therapy. New York, Appleton-CenturyCrofts, 1956.

23. Cooper, J., Moodley, M., Reynell, J. (1979) 'The developmental language programme. Results from a five year study.' British Journal of Disorders of Communication. 14, 57-59. 